DOE/ER/13299--9

DE93 013382

\title{
DIOSMACYCLOALKANES AS MODELS FOR THE FORMATION OF HYDROCARBONS FROM SURFACE METHYLENES
}

\author{
Progress Report
}

For the Period November 1, $1993^{2}$ - October 31, $199 a^{3}$

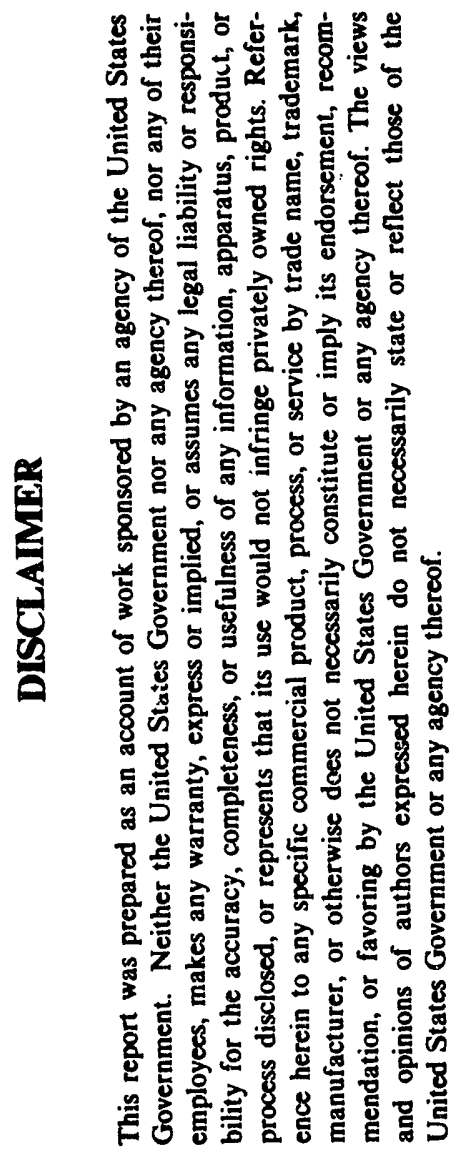

\author{
Jack R. Norton \\ Colorado State University \\ Fort Collins, Colorado 80523
}

May 1, 1993

Prepared for

THE U.S. DEPARTMENT OF ENERGY

AGREEMENT NO. DE-FG02-84ER13299-A06 


\section{Report of Progress to Date}

\section{Department of Energy (Grant \#FG02-84ER13299) \\ lack R. Norton, Principal Investigator}

\section{A. Vibrational Models for Surface Ethylidenes}

A manuscript describing this work is now being assembled by $C$. Anson and $N$. Sheppard, our collaborators at the U. of East Anglia (UK). Both groups have written their contributions, and the final manuscript will have been submitted for publication by the time this proposal is reviewed.

Goal: a vibrational "fingerprint" of $\mathrm{CH}_{3} \mathrm{CH}$ so that it can be identified on metal catalyst surfaces

We have developed the following method for the preparation of $\mathrm{CH}_{3} \mathrm{CD}(\mathrm{OTf})_{2}$ and $\mathrm{CD}_{3} \mathrm{CD}(\mathrm{OTf})_{2}$, and have used these labelled geminal ditriflates for the preparation of $\mathrm{Os}_{2}(\mathrm{CO})_{8}\left(\mu-\mathrm{CDCH}_{3}\right)$ and $\mathrm{Os}_{2}(\mathrm{CO})_{8}\left(\mu-\mathrm{CDCD}_{3}\right)$.

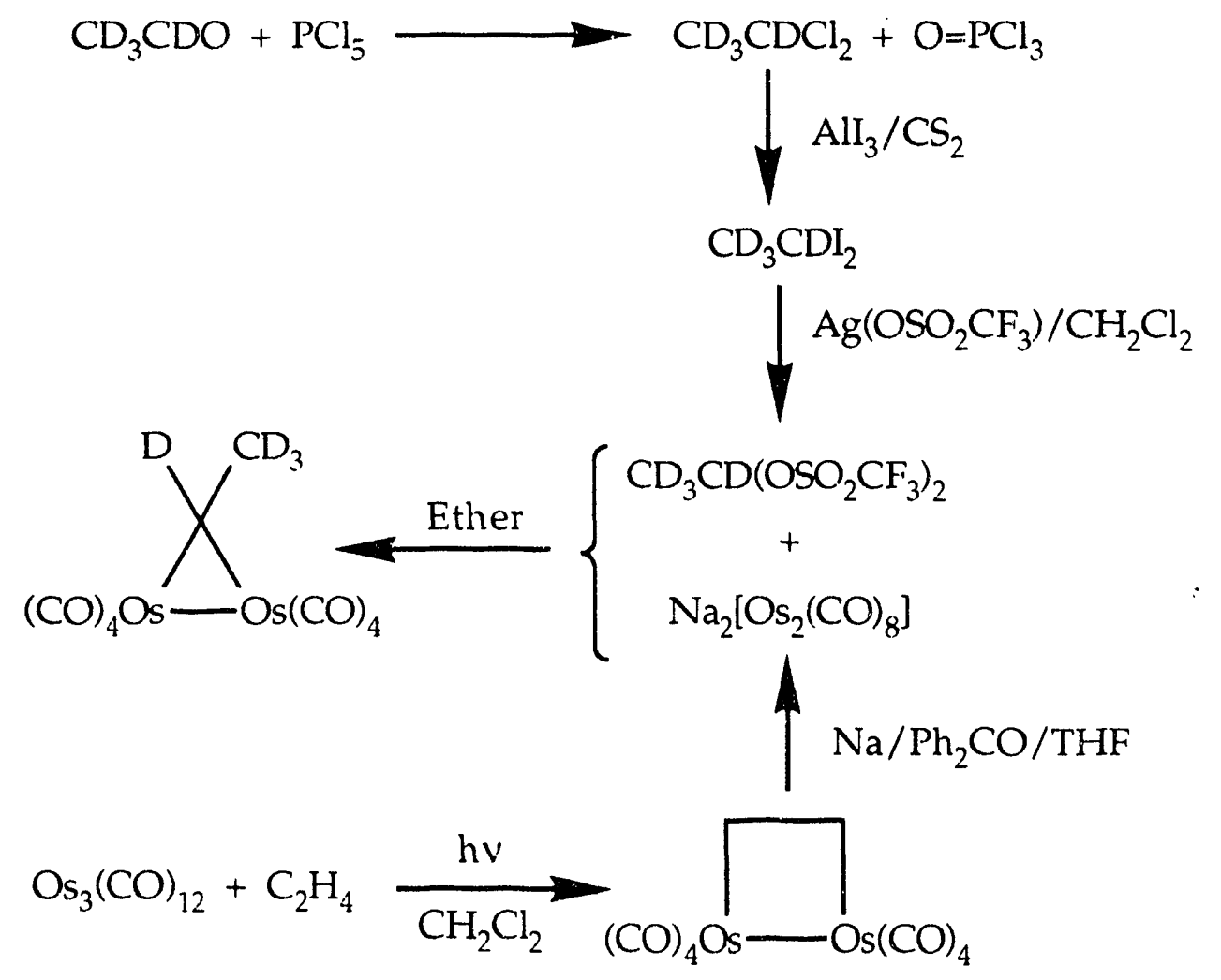

In collaboration with Anson and Sheppard we have obtained lowtemperature infrared and Raman spectra of these labelled diosmacyclopropanes and used them to assign the vibrational modes of the bridging ethylidene ligands (Table I). After comparison with the well-established vibrational assignments for $\mathrm{CH}_{3} \mathrm{CHX}_{2}{ }^{1}$ the assignments of the diosmacyclopropane modes are unequivocal, although the $\mathrm{CD}_{3} \mathrm{CD}$ modes identified with an asterisk are strongly coupled. 


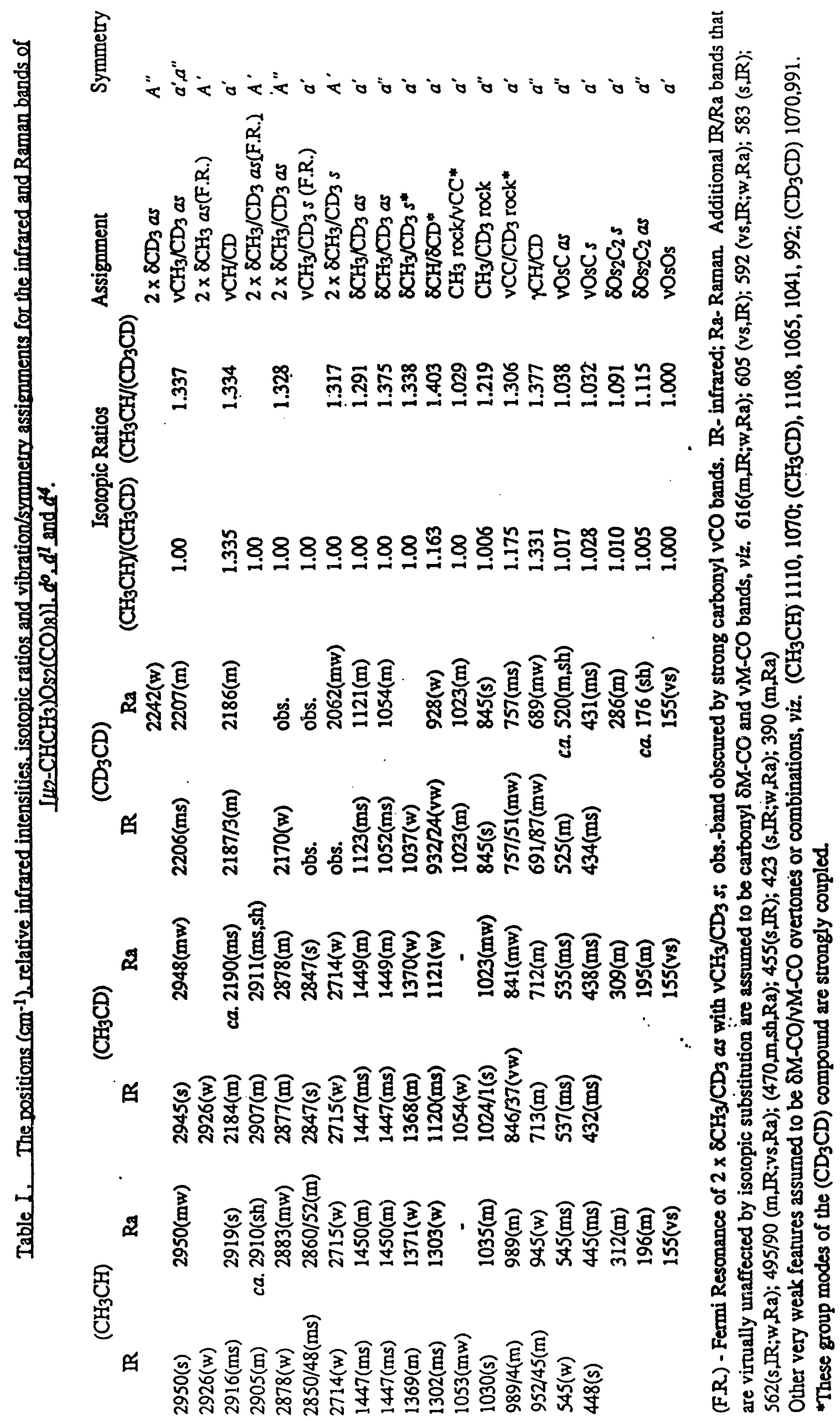


Previously reported surface ethylidenes ${ }^{2}$ have turned out to be ethylidynes $\left(\mathrm{CH}_{3} \mathrm{C}\right){ }^{3}$ The information in Table I should enable the identification of an ethylidene species on the surface of a catalyst. Two apparent examples, shown in Table II, arise from (1) the adsorption of ethylene onto $\mathrm{Pt}(111)$ with preadsorbed oxygen, ${ }^{3 \mathrm{c}}$ and (2) hydrogenation of $\mathrm{CO}$ adsorbed on $\mathrm{Rh} / \mathrm{Al}_{2} \mathrm{O}_{3}{ }^{4}$

Table II. The assigned fundamentals $(\mathrm{cm}$-1) for the ethylidene groups in several metal coordination compounds and for possible ethylidene species on metal surfaces

\begin{tabular}{|c|c|c|c|c|}
\hline \multicolumn{2}{|c|}{$\left(\mu_{2}-C D C D_{3}\right) \mathrm{O}_{2}(C O)_{8}$} & \multirow[t]{2}{*}{$\left(\mu_{2}-\mathrm{CHCH}_{3}\right) \mathrm{Os}_{2}(\mathrm{CO})_{8}$} & \multirow{2}{*}{$\mid \begin{array}{l}\mathrm{CO} / \mathrm{H}_{2 /} \\
\mathrm{Rh} / \mathrm{Al}_{2} \mathrm{O}_{3}\end{array}$} & \multirow{2}{*}{$\begin{array}{l}\mathrm{C}_{2} \mathrm{H}_{4} / \\
\mathrm{Pt}(111) / \mathrm{O}\end{array}$} \\
\hline \multicolumn{2}{|c|}{$a^{\prime}$ modes } & & & \\
\hline 2207 & $v \mathrm{CH}_{3} / \mathrm{CD}_{3}$ as & 2950 & $2964(s, b)$ & $2980(\mathrm{~ms}, \mathrm{~b})$ \\
\hline 2187 & $\vee C H / C D$ & 2918 & $2916(s, b)$ & \\
\hline- & $v \mathrm{vH}_{3} / \mathrm{CD}_{3} \mathrm{~s}$ & 2847 & & \\
\hline 1123 & $8 \mathrm{CH}_{3} / \mathrm{CD}_{3}$ as & 1449 & 1463(ms) & $1460(s)$ \\
\hline 1037 & $\mathrm{CCH}_{3} / \mathrm{CD}_{3} \mathrm{~s}$ & 1369 & 1378(m) & $1380(\mathrm{~ms}, \mathrm{vb})$ \\
\hline 1023 & $\delta C H / C D$ ip & 1302 & $1256(\mathrm{~m})$ & $1380(\mathrm{~ms}, \mathrm{vb})$ \\
\hline 928 & $\rho \mathrm{CH}_{3} / \mathrm{CD}_{3}$ & 1053 & $1058(\mathrm{~m})$ & \\
\hline 757 & $v C C$ & 989 & $940(\mathrm{mw})$ & $940(m)$ \\
\hline 434 & vOsCs & 448 & & 480 (vs) \\
\hline 286 & $8 \operatorname{ccos} s$ & 312 & & $300(\mathrm{~m})$ \\
\hline 155 & vOsOs & 155 & & \\
\hline \multicolumn{5}{|c|}{$e^{\prime \prime}$ modes } \\
\hline (2207) & $v \mathrm{CH}_{3} / \mathrm{CD}_{3}$ as & $(2950)$ & & \\
\hline 1054 & $\mathrm{CCH}_{3} / \mathrm{CD}_{3}$ as & (1449) & & \\
\hline 845 & $\rho \mathrm{CH}_{3} / \mathrm{CD}_{3}$ & $1030^{\circ}$ & & \\
\hline 689 & $\delta \mathrm{CH} / \mathrm{CD}$ oop & 945 & & \\
\hline 525 & vOsC as & 545 & 594 (ms) & \\
\hline ca 176 & $\delta C \operatorname{COs} 00 p$ & 196 & & \\
\hline
\end{tabular}

B. "Alpha vs. Beta Hydrogen Elimination in the Formation of Propene from an Osmacyclobutane", W. Fischer, R.T. Hembre, D.R. Sidler, and J.R. Norton, Inorg. Chim. Acta, 1992, 198-200, 57.

Question to be Answered: does $\alpha$-elimination play a role in the fragmentation of metallacyclobutanes?

We have examined the fragmentation of the osmacyclobutane below in a gasphase flow system. We have found the only product to be propylene, with no evidence for the cyclopropane Lindner ${ }^{5}$ has reported. Control experiments have shown that the deuterium content and distribution of propylene remain unaffected after it is formed. Over half the propylene is formed by the expected $\beta$ elimination. However, the formation of a significant amount of $\mathrm{CH}_{3} \mathrm{CD}=\mathrm{CHD}$ shows that, contrary to the conventional wisdom, some $\alpha$ elimination is occurring. 


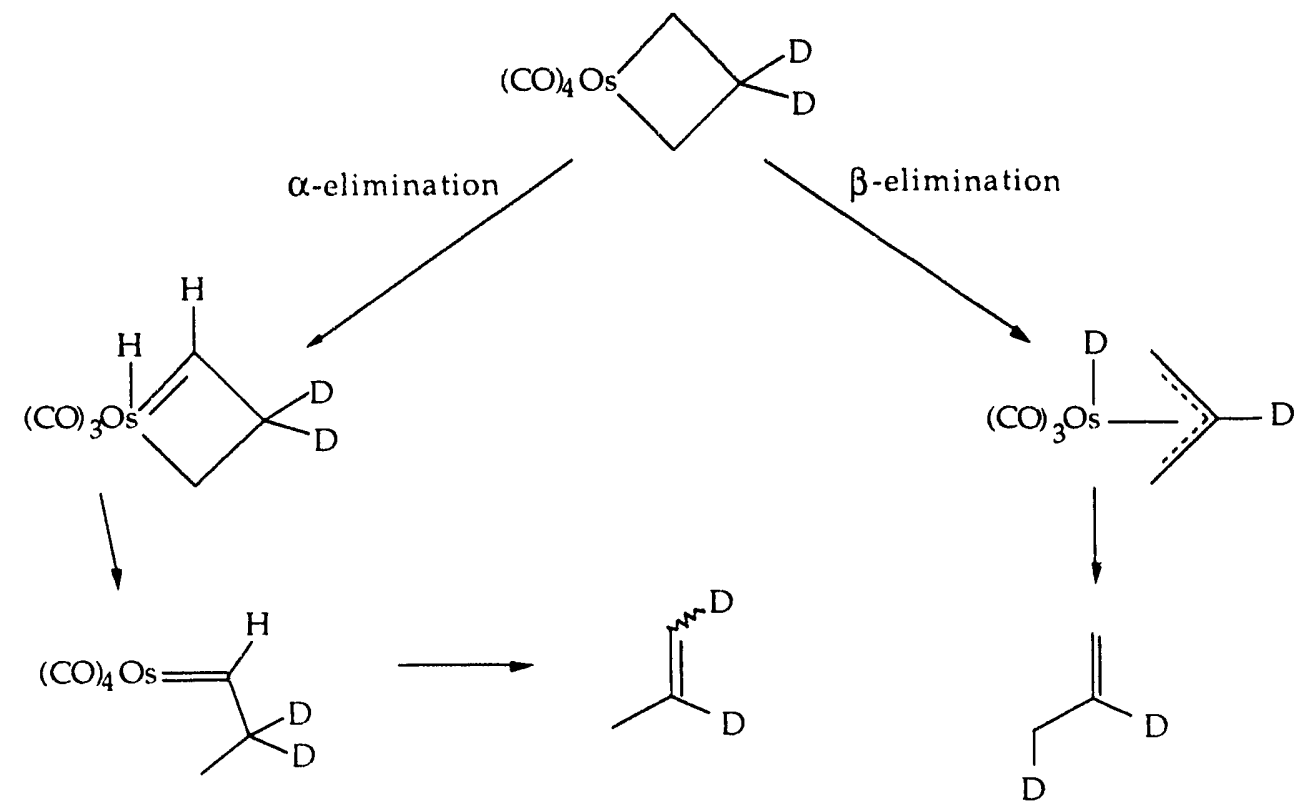

\section{Mechanism of the formation and fragmentation of diosmacyclobutanes.}

Publications that have appeared during 1990-93:

(a) "The Photochemistry of Dinuclear Osmium Carbonyl Complexes; Characterization of $\mathrm{Os}_{2}(\mathrm{CO})_{8}$ Using Matrix Isolation", A. Haynes, M. Poliakoff, J.J. Turner, B. Bender and J.R. Norton, J. Organomet. Chem. 1990, 383, 497.

(b) "A Single Crystal Neutron Diffraction Study of $\left(\mu-\eta^{1}, \eta^{1}-\mathrm{C}_{2} \mathrm{H}_{4}\right) \mathrm{Os}_{2}(\mathrm{CO})_{8}, \mathrm{~A}$ Model for One Type of Chemisorbed Ethylene", O.P Anderson, B.R. Bender, J.R. Norton*, A.C. Larson*, and P.J. Vergamini, Organometallics 1991, 10, 3145.

Two additional publications based on the material below are in draft form. Additional publications are in preparation describing (1) the structure of $(\mu-$ $\left.\mathrm{C}_{2} \mathrm{H}_{4}\right) \mathrm{Os}_{2}(\mathrm{CO})_{8}$ in a nematic phase solvent, and (2) evidence that ethylene in diosmacyclobutanes does not rotate prior to exchange, as well as $\mathrm{H} / \mathrm{D}$ isotope effects on their exchange.

Goal: (long-term) understanding the factors that determine stereochemistry during metallacycle formation and cleavage; (immediate) explaining why the loss of olefins from $\left(\mu\right.$-olefin) $\mathrm{Os}_{2}(\mathrm{CO})_{8}$ is stereospecific when that from the analogous cyclobutane is not.

An example of olefin exchange by a diosmacyclobutane is shown below.<smiles>CCCCOC(=O)C1CC(C(=O)OCCC)O1</smiles> 
Any proposed mechanism must explain the high stereospecificity observed in these reactions ${ }^{6}$ in contrast to the complete loss of stereochemistry in the fragmentation of the isolobal cyclobutane. ${ }^{7}$

Four possible mechanisms are shown on the following page. We have ruled out mechanism IV (simple associative) in view of the observation of saturation behavior as [BA] is increased. Mechanism I (simple dissociative) is an apparent violation of the symmetry rules for cycloadditions. Mechanisms II and III involve a "ring-opened" species 1 that we (publication a above) and others ${ }^{8}$ have seen in matrix isolation and transient IR experiments. As olefins coordinated to a single metal are known to exchange stereospecifically, the involvement of 1 offers an attractive explanation of the stereospecificity of these exchange reactions.

Mechanisms analogous to II and III have been proposed by Anslyn and Grubbs ${ }^{9}$ for titanacyclobutane cleavage; 1 is isolobal to the alkylidene olefin complexes they propose as intermediates.

Some evidence in favor of the intermediacy of 1 is offered by looking at exchange rates as a function of the departing olefin. The propene adduct of $\mathrm{Os}_{2}(\mathrm{CO})_{8}$ undergoes exchange more rapidly than the trans-2-butene adduct! This observation is contrary to the normal rules of olefin complex stability 10

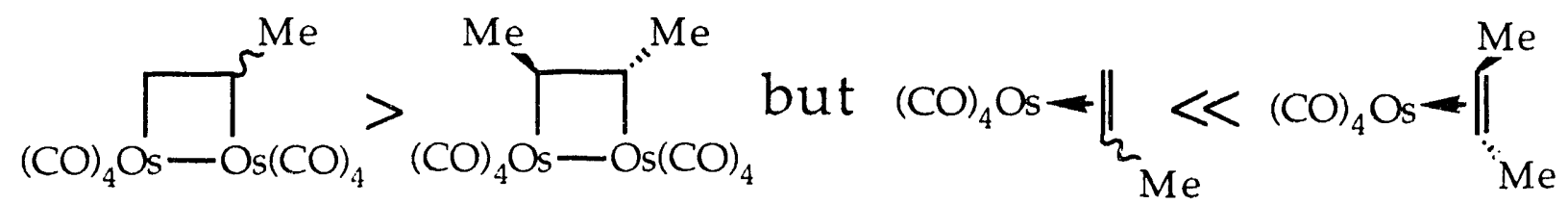

as exemplified by the mononuclear Os olefin complexes shown above. We have confirmed that the olefin dissociation rate constant $k_{5}$ is much faster for $\mathrm{Os}(\mathrm{CO})_{4}$ (trans-2-butene) than for $\mathrm{Os}(\mathrm{CO})_{4}$ (propene). (We observe the saturation behavior expected for the mechanism shown - a mechanism analogous to that established for the analogous tetracarbonyl iron olefin system. ${ }^{11}$ )

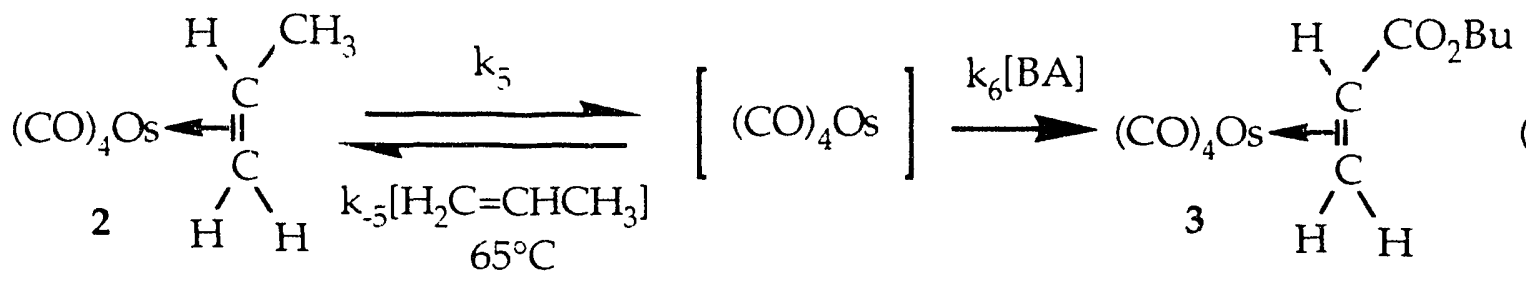

We attribute the anomalous stability of the $\mathrm{Os}_{2}(\mathrm{CO})_{8}($ trans-2-butene) adduct to unfavorable steric interactions in the ring-opened intermediate 1 . This is consistent with the results of molecular modeling studies performed in collaboration with Professor Anthony K. Rappé at CSU. Those studies indicate that the trans-2-butene version of 1 is destabilized at least $3 \mathrm{kcal} / \mathrm{mol}$ relative to its ethylene and propene analogs, due to close contact between the interior methyl group and a carbonyl on the adjacent Os atom (see page 7 ). This destabilization leads to relatively lower concentrations of the intermediate 1 , and lower overall rates of exchange, in the trans-2-butene case. 


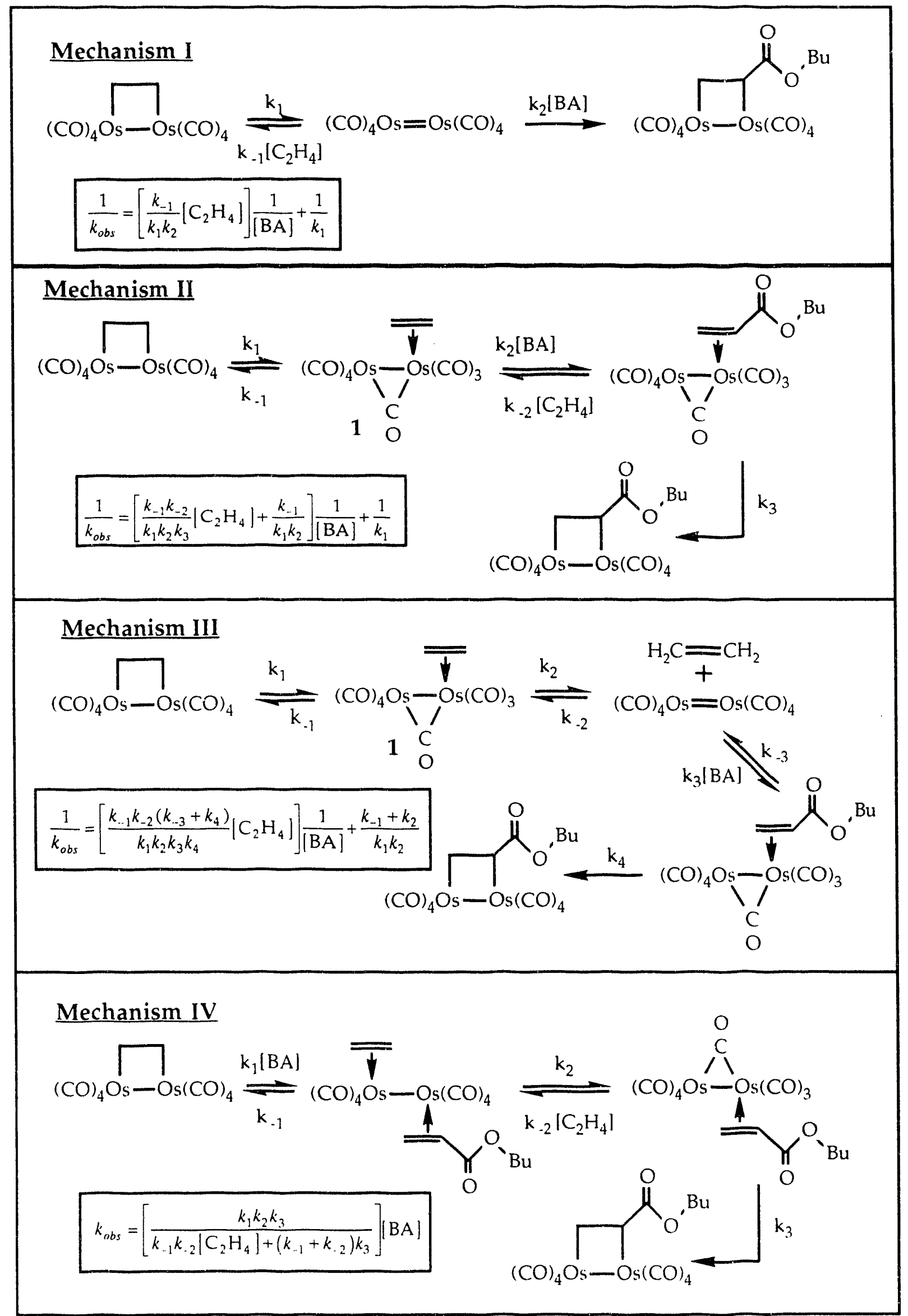




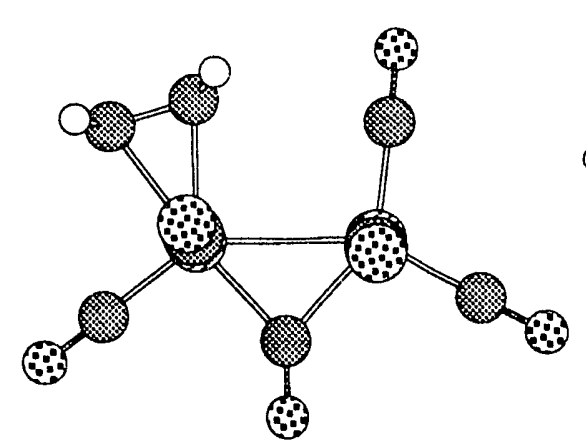

1-ethylene

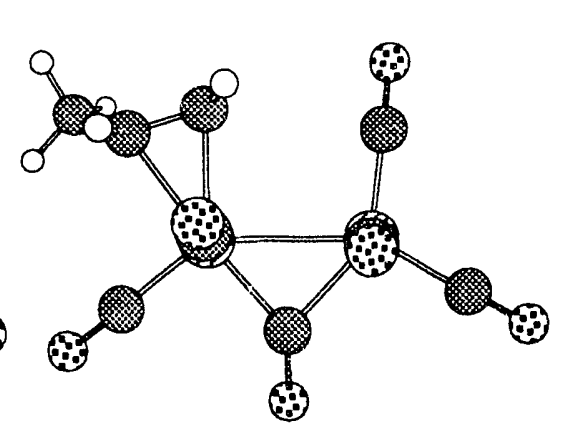

1-propene

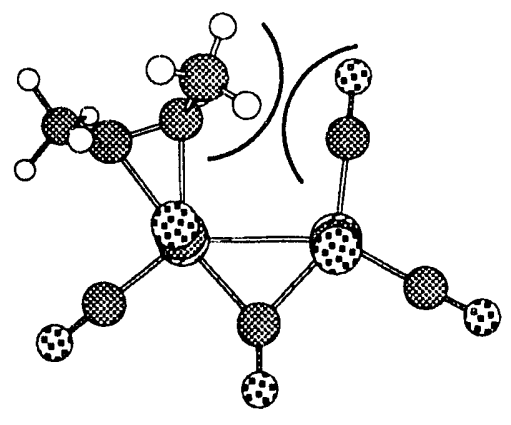

1-trans-2-butene

We have found that diosmacyclobutane exchange reactions like (1) proceed by the ring-opening/associative exchange mechanism: mechanism II. Both mechanisms II and III predict that a plot of $1 / \mathrm{k}_{o b s}$ vs. [BA] at constant $\left[\mathrm{C}_{2} \mathrm{H}_{4}\right]$ should yield a straight line, the slope of which should show positive $\left[\mathrm{C}_{2} \mathrm{H}_{4}\right]$ dependence. Such slopes must be related to $\left[\mathrm{C}_{2} \mathrm{H}_{4}\right]$ by one of the following equations, if mechanism II or III is operative. Thus, if the slope from a $1 / \mathrm{k}_{o b s}$ vs. [BA] plot is plotted vs. $\left[\mathrm{C}_{2} \mathrm{H}_{4}\right]$, a nonzero intercept should be obtained if mechanism II is the operative mechanism and a zero intercept otherwise.

\section{Mechanism II}

$$
\text { slope }=\left[\frac{k_{-1} k_{-2}}{k_{1} k_{2} k_{3}}\right]\left[\mathrm{C}_{2} \mathrm{H}_{4}\right]+\frac{k_{-1}}{k_{1} k_{2}}
$$

\section{Mechanism III}

$$
\text { slope }=\left[\frac{k_{-1} k_{-2}\left(k_{-3}+k_{4}\right)}{k_{1} k_{2} k_{3} k_{4}}\right]\left[\mathrm{C}_{2} \mathrm{H}_{4}\right]
$$

We have obtained slopes from numerous $1 / \mathrm{k}_{o b s} v s$. [BA] plots and plotted these slopes vs. $\left[\mathrm{C}_{2} \mathrm{H}_{4}\right]$. Unfortunately, the solubility of $\mathrm{C}_{2} \mathrm{H}_{4}$ proved to vary as a function of $[\mathrm{BA}]$ and the simple graphical method described above did not give a solution. In collaboration with Professor James P. Kohn of the Chemical Engineering department at Notre Dame University we experimentally measured the solubility of $\mathrm{C}_{2} \mathrm{H}_{4}$ as a function of [BA] and were then able to calculate the actual $\left[\mathrm{C}_{2} \mathrm{H}_{4}\right]$ for each of our kinetic experiments. Multiple regression of the kinetic data implicated mechanism II.

The mononuclear substitution reaction in eq 2 shows a complication that provides insight into the mechanism of this reaction. At lower concentrations of BA the diosmacyclobutane $\mathrm{Os}_{2}(\mathrm{CO})_{8}\left(\mu-\eta, \eta^{\prime}-\mathrm{H}_{2} \mathrm{C}=\mathrm{CHCO}_{2} \mathrm{Bu}\right)$ is observed as a coproduct from the mononuclear olefin exchange reaction. No induction period is observed in the formation of this binuclear product, and the $3 / 4$ ratio decreases with decreasing BA concentration. These results suggest the following mechanism of formation. The resulting rate law, written in terms of disappearance of the starting material 1, correctly predicts the behavior of the system as [BA] is varied. The observation that significant amounts of 4 are formed at low [BA] provides compelling evidence (in addition to the saturation kinetics already noted at high [BA]) for the intermediacy of $\mathrm{Os}(\mathrm{CO})_{4}$ in eq 2. 


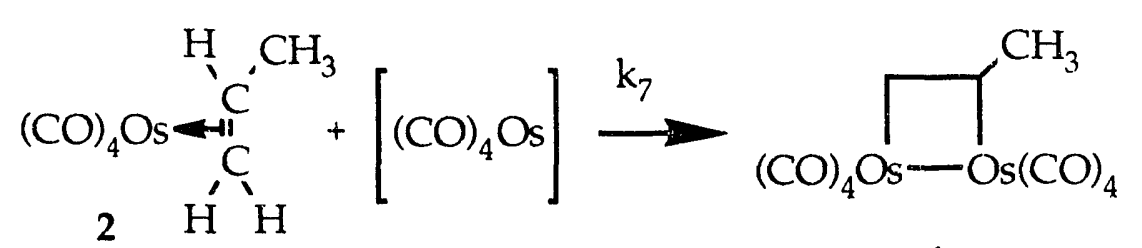

$2 \mathrm{H} \quad \mathrm{H}$<smiles>CC(C)(Br)CC(C)(C)C(C)(C)Br</smiles><smiles>CC(=O)OC(=O)C1CC1OC(C)(C)C</smiles>

4

$$
-\frac{\mathrm{d}[2]}{\mathrm{dt}}=\frac{k_{5} k_{6}[2][\mathrm{BA}]+k_{5} k_{7}[2]^{2}}{k_{-5}\left[\mathrm{H}_{2} \mathrm{C}=\mathrm{CHCH}_{3}\right]+k_{6}[\mathrm{BA}]+k_{7}[2]}
$$

\section{Reaction of dienes and allenes with diosmacyclobutanes}

Question to be Answered: Do dienes add 1,2 or 1,4 to $\mathrm{Os}_{2}(\mathrm{CO})_{8}$ ?

Our conclusion in the preceding section (that Mechanism II is correct) implies that the exchange reactions of diosmacyclobutanes do not involve free $(\mathrm{CO})_{4} \mathrm{Os}=\mathrm{Os}(\mathrm{CO})_{4}$. However, before that result had been established we decided to investigate whether these reactions gave 1,4 or 1,2 addition products when the $(\mathrm{CO})_{4} \mathrm{Os}=\mathrm{Os}(\mathrm{CO})_{4}$ unit was transferred to a diene. The former (1,4 addition) is of course observed when a carbon-carbon double bond reacts with a diene, and would be expected with free $(\mathrm{CO})_{4} \mathrm{Os}=\mathrm{Os}(\mathrm{CO})_{4}$ (Scheme I).

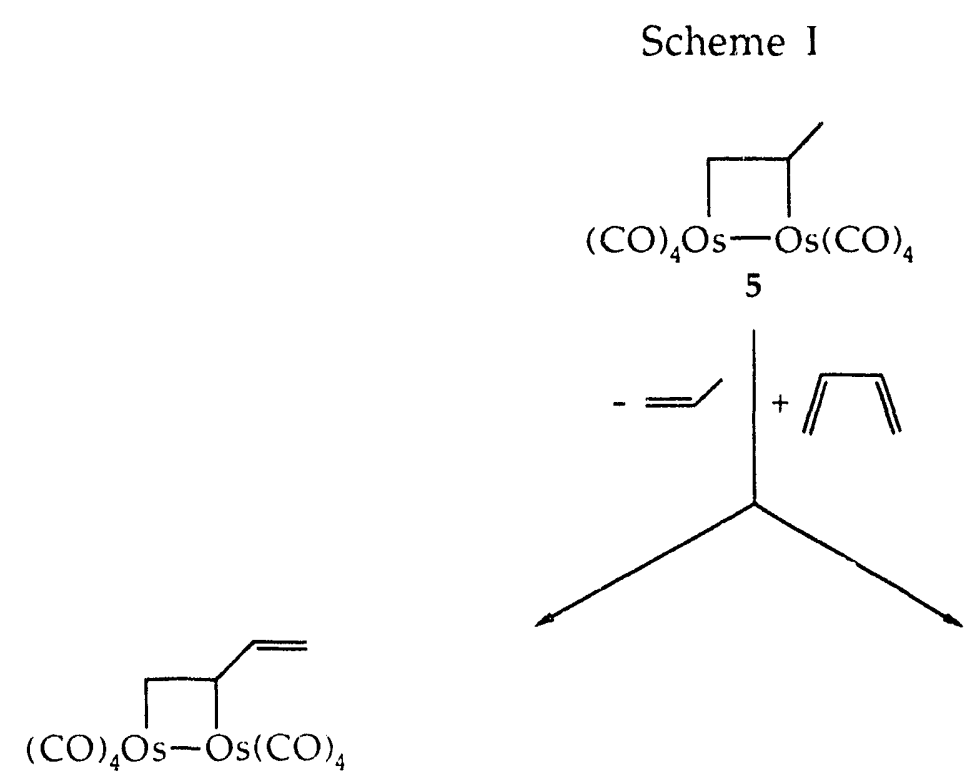

(1, 2-addition product)

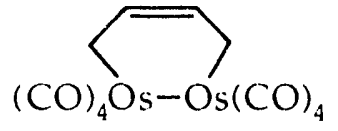

(1, 4 -addition product) 
Instead, the reaction between the diosmacyclobutane 5 and butadiene (eq 4) gave the 1,2 addition product 6 along with compounds 7 and 8 . The kinetic product 6 rearranges to 7 .
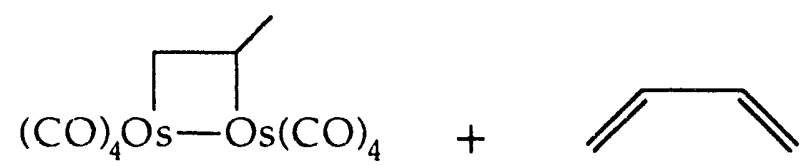

5

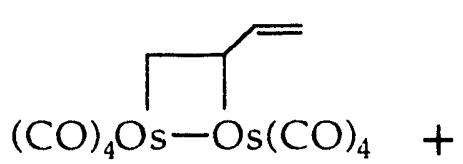

6

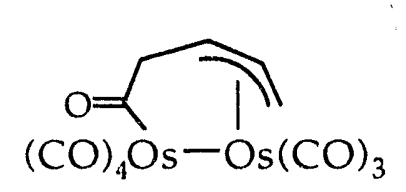

7

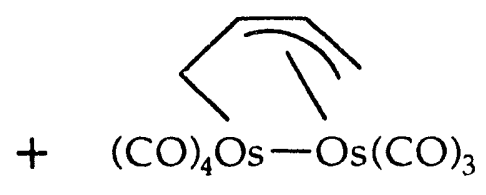

8

Compound 8 is also obtained from the reaction of $\left[\mathrm{Os}_{2}(\mathrm{CO})_{8}\right]^{2-}$ with either cisor trans $-\mathrm{ClCH}_{2} \mathrm{CH}=\mathrm{CHCH}_{2} \mathrm{Cl}$ or with $\mathrm{CH}_{2}=\mathrm{CHCHClCH}_{2} \mathrm{Cl}$. Photolysis of $\mathrm{Os}_{3}(\mathrm{CO})_{12}$ in the presence of butadiene gives the dinuclear compounds $\mathbf{7}$ and $\mathbf{8}$ as well as $\mathrm{Os}(\mathrm{CO})_{3}$ (butadiene).

The transfer of the $(\mathrm{CO})_{4} \mathrm{Os}=\mathrm{Os}(\mathrm{CO})_{4}$ unit to an allene also occurs by 1,2 addition (eq 5).

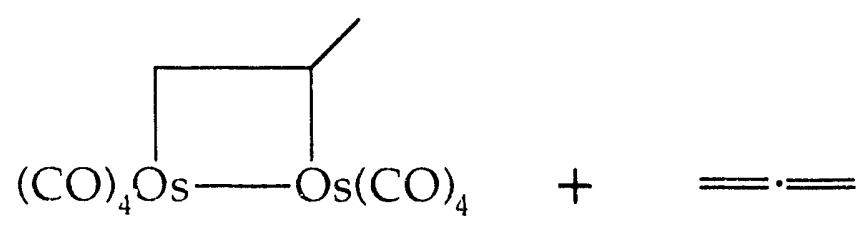

5

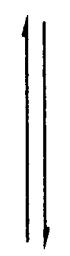<smiles>CC(=O)OC1C=CC1OC(C)=O</smiles>

9

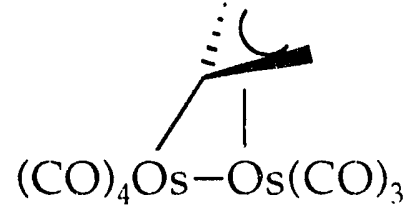

10 
The kinetic product 9 rearranges to the more thermodynamically stable and previously reported 1210 . (The 1,2 addition product 9 represents a new bonding mode for allene as a bridging ligand in dinuclear centers. ${ }^{13}$ ) Photolysis of $\mathrm{Os}_{3}(\mathrm{CO})_{12}$ in the presence of allene gives Os(CO) $($ allene) and 10 (eq 6).

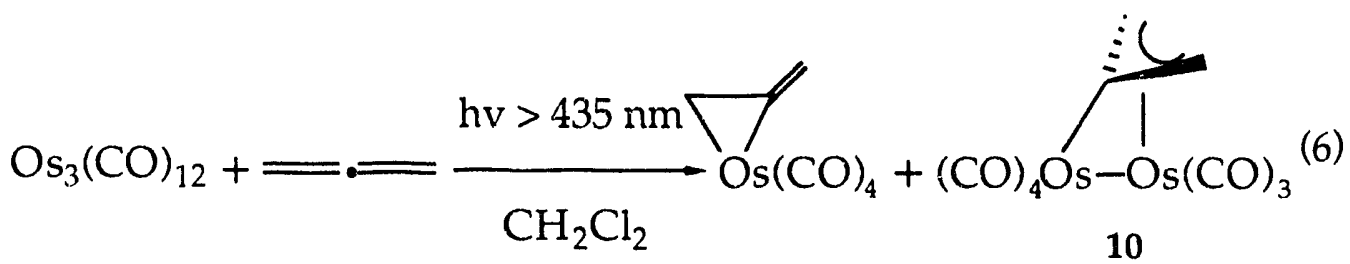

The observation of 1,2 addition products in both of the above cases is consistent with, and indeed predicted by, the mechanism established in Section C.

E. "The Structure of Os(CO) ${ }_{4}\left(\mathrm{C}_{2} \mathrm{H}_{4}\right)$, an Osmacyclopropane", B.R. Bender, J.R. Norton*, M.M. Miller, O.P. Anderson, and A.K. Rappé*, Organometallics 1992, 11, 3427-3434.

A nearly complete draft of another publication - describing the structure of $\mathrm{Os}(\mathrm{CO})_{4}\left(\mathrm{C}_{2} \mathrm{H}_{4}\right)$ in a nematic phase solvent - was written almost a year ago. It lacks only the appropriate vibrational corrections, which require the normal mode data that our collaborators at East Anglia (Anson and Sheppard) have promised but not yet delivered.

Question to be Answered: how much osmacyclopropane character does $\mathrm{Os}(\mathrm{CO})_{4}\left(\mathrm{C}_{2} \mathrm{H}_{4}\right)$ possess? Goal: synthesis of coordinatively unsaturated alkyl carbonyl cations

The value of ${ }^{1} J_{13} \mathrm{C}-13 \mathrm{C}$ for an ethylene coordinated to $\mathrm{Os}(\mathrm{CO})_{4}$ has been determined from the ${ }^{1} \mathrm{H}$ NMR spectrum of $\mathrm{Os}(\mathrm{CO})_{4}\left(\eta^{2}-{ }^{13} \mathrm{C}_{2} \mathrm{H}_{4}\right)$. X-ray analysis shows the geometry of $\mathrm{Os}(\mathrm{CO})_{4}\left(\eta^{2}-\mathrm{C}_{2} \mathrm{H}_{4}\right)(11)$ to be approximately tr.gonal bipyramidal, with the ethylene carbons twisted out of the equatorial plane by $4.0^{\circ}$. The axial carbonyls of $\mathbf{1 1}$ tilt toward the coordinated ethylene, with a $\mathrm{C} 1-\mathrm{Os}-\mathrm{C} 1{ }^{\prime}$ angle of $171.3(5)^{\circ}$. The optimal geometries of $\mathrm{Os}(\mathrm{CO})_{4}, \mathrm{H}_{2} \mathrm{Os}(\mathrm{CO})_{4}$, and $\mathbf{1 1}$ have been calculated by Hartree Fock methods. The orbital amplitude contour diagrams of a GVB(6/12) wavefunction for 11 show that the axial bending occurs in order to mix in virtual $p_{\pi}$ character and improve backbonding to the equatorial carbonyls; they also show that $\mathbf{1 1}$ is best described as a metallacyclopropane.

One would thus expect the kinetic site of electrophilic attack on $\mathbf{1 1}$ to be carbon, despite the strength of the Os-H bond. We have therefore begun to examine the protonation of $\mathbf{1 1}$ by acids with weakly coordinating anions. (The potential uses of the cations thereby generated will be discussed in "Plans for Future Research".) 


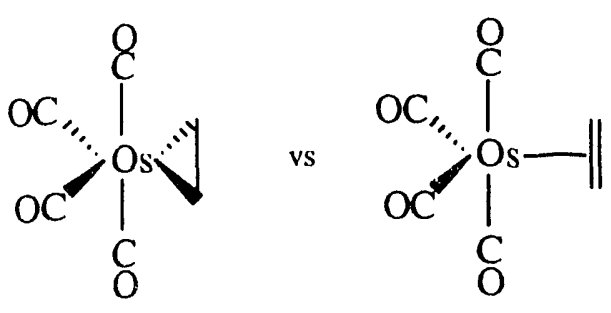

Use of $\mathrm{HBF}_{4} \bullet \mathrm{Me}_{2} \mathrm{O}$ in $\mathrm{CH}_{2} \mathrm{Cl}_{2}$ gives the insoluble 12 with $\eta^{1}-\mathrm{BF}_{4}^{-}$; the $\mathrm{BF}_{4}^{-}$is displaced by coordinating solvents such as acetone to give 13 Use of $\mathrm{CF}_{3} \mathrm{SO}_{3} \mathrm{H}$ gives the soluble 14. We have seen no evidence for $\mathrm{Os}-\mathrm{H}$ bond formation, or even for an agostic interaction between the $\mathrm{Os}$ and a $\mathrm{C}-\mathrm{H}$ bond.

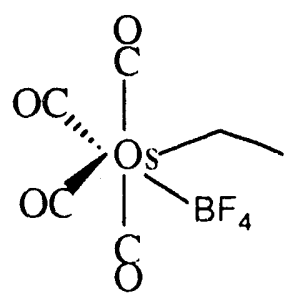

12<smiles>CCC(C)(O)OC(C)=O</smiles><smiles>CCO[Cl+3]([O-])([O-])[O-]</smiles>

14

Like $\mathrm{CpRe}(\mathrm{CO})_{2}$ (alkene) complexes, ${ }^{14} \mathrm{Os}(\mathrm{CO})_{4}$ complexes of substituted olefins give cationic allyl complexes when treated with $\mathrm{Ph}_{3} \mathrm{C}^{+}$. For example, $\mathrm{Os}(\mathrm{CO})_{4}\left(\mathrm{CH}_{3} \mathrm{CH}=\mathrm{CH}_{2}\right)$ gives $\left[\mathrm{Os}(\mathrm{CO})_{4}\left(\mathrm{CH}_{2} \mathrm{CHCH}_{2}\right)\right]^{+}$, and $\mathrm{Os}(\mathrm{CO})_{4}\left(\mathrm{CH}_{3} \mathrm{CH}_{2} \mathrm{CH}=\mathrm{CH}_{2}\right)$ gives $\left[\mathrm{Os}(\mathrm{CO})_{4}\left(\mathrm{CH}_{3} \mathrm{CHCHCH}_{2}\right)\right]+$.

F. "Reaction of $\mu$-Oxobis[(trifluoromethanesulfanato)(phenyl)iodine(III)] with Group 14 Propargyl Derivatives and a Propargyl Ether", D.A. Gately, T.A. Luther, J.R. Norton*, M.M. Miller, and O.P. Anderson, J. Org. Chem. 1992, 57, 6496-6502.

Question to be Answered: does $[\mathrm{PhI}(\mathrm{OTf})]_{2} \mathrm{O}$ react with alkynec in any useful way? (We used the reaction of this reagent with olefins to generate the vicinal ditriflates required for the synthesis of diosmacyclobutanes.)

We have discovered a novel allenyl "Claisen" rearrangement while exploring the reactions of an I(III) reagent with triple bonds. ${ }^{15}$ We have shown that the intramolecular H/D isotope effect is negligible, as previously reported ${ }^{16}$ for the Claisen rearrangement of 2-deuteriophenyl propargyl ether. 


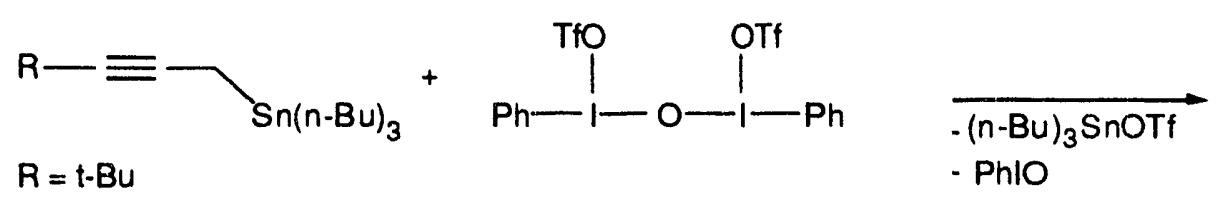<smiles>[R]C#CCC1C=CC=CC1=IO</smiles>

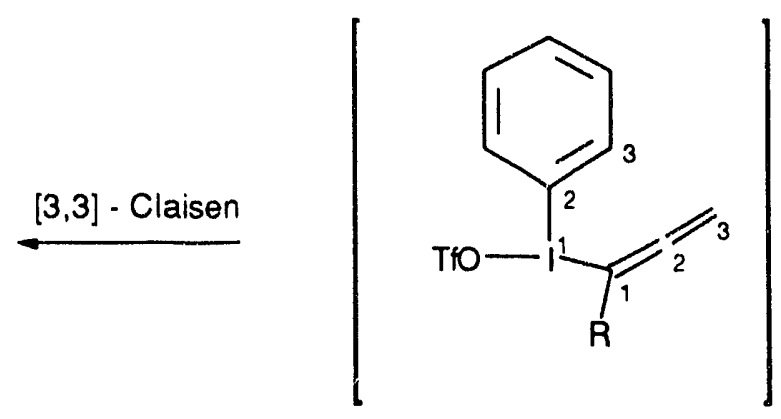<smiles>[R]C#CCc1ccccc1I</smiles>

proposed allenyliodinane

We have discovered that a side chain ether oxygen can control the regioselectivity with which the reagent adds to triple bonds. The reaction below gives only the product shown.
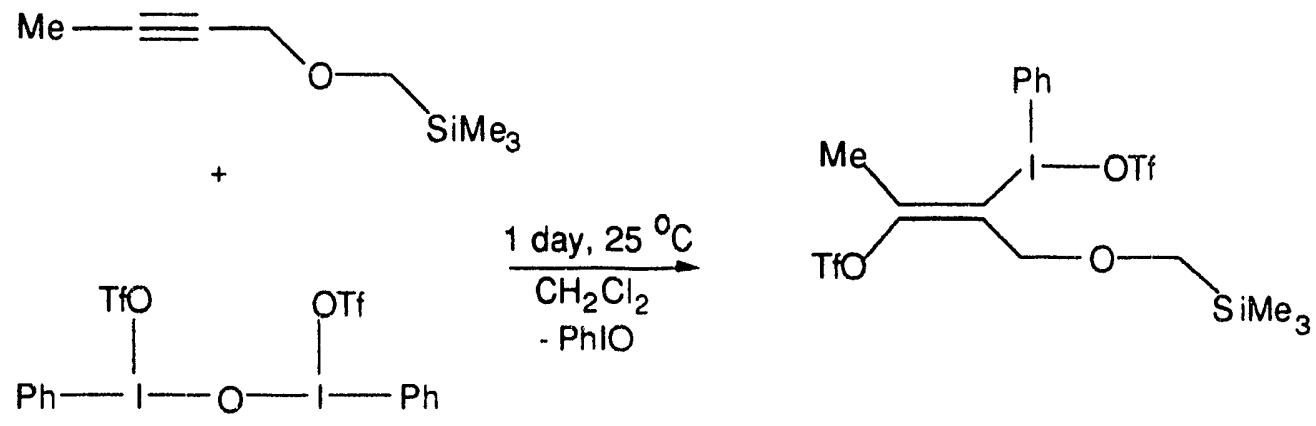


\section{REFERENCES}

1Durig, J. R.; Sloan, A. E.; Witt, J. D. J. Phys. Chem. 1972, 76, 3591, and Durig, J. R.; Sloan, A. E.; Thompson, J. W.; Witt, J. D. J. Chem. Phys. 1974, 60, 2260.

2Ibach, H.; Lehwald, W. J. Vac. Sci. Technol. 1978, 15, 407.

3(a) Kesmodel, L. L.; Dubois, L. H.; Somorjai, G. A. J. Chem. Phys. 1979, 70, 2180. (b) Skinner, P.; Howard, M. W.; Oxton, I. A.; Kettle, S. F. A.; Powell, D. B.; Shappard, N. J. Chem. Soc. Faraday Trans. 2 1981, 77, 1203. (c) Steininger, H.; Ibach, H.; Lehwald, S. Surf. Sci. 1982, 117, 685.

${ }^{4}$ Kroeker, R. M.; Kaska, W. C.; Hansma, P. K. J. Catal. 1980, 61, 87.

5Lindner, E.; Jansen, R.-M.; Hiller, W.; Fawzi, R. Chem. Ber. 1989, 122, 1403. 6 Hembre, R. T.; Scott, C. P.; Norton, J. R. J. Am. Chem. Soc. 1987, 109, 3468-3470.

7(a) Chickos, J. S.; Annamalai, A.; Keiderling, T. A. J. Am. Chem. Soc. 1986, 108, 43984402. (b) Chikos, J. S. J. Org. Chem. 1979, 44, 780-784.

8 Grevels, F.-W.; Klotzbücher, W. E.; Seils, F.; Schaffner, K.; Takats, J. J. Am. Chem. Soc. 1990, 112, 1995.

${ }^{9}$ (a) Anslyn, E. V.; Grubbs, R. H. J. Am. Chem. Soc. 1987, 109, 4880. (b) Finch, W. C.; Anslyn, E. V.; Grubbs, R. H. J. Am. Chem. Soc. 1988, 110, 2406. (c) Hawkins, J. M.; Grubbs, R. H. 1988, 110, 2821.

10(a) Hartley, F. R. Chem. Rev. 1969, 69, 799-844. (b) Henry, P. M. J. Am. Chem. Soc. 1966, 88, 1595-1597.

11Cardaci, G.; Narciso, V. J. J. Chem. Soc., Dalton Trans. 1972, 2289-2293.

12Deeming, A. J.; Arce, A. J.; De Sanctis, Y. J. Chem. Soc., Dalton Trans. 1987, 2935.

13(a) Chacon, S. T.; Chisholm, M. H.; Folting, K.; Huffman, J. C.; Hampden-Smith, M. J. Organometallics 1991, 10, 3722. (b) Seyferth, D.; Anderson, L. L.; Davis, W. B.; Cowie, LM. Organometallics 1992, 11, 3736.

14Casey, C. P.; Yi, C. S. Organometallics 1990, 9, 2413.

15 Similar chemistry has been reported by Ochiai and co-workers: (a) Ochiai, M.; Ito, T.; Takaoka, Y.; Masaki, Y. J. Am. Chem. Soc. 1991, 113, 1319. (b) Ochiai, M.; Ito, T.; Masaki, Y.J. Chem. Soc., Chem. Commun. 1992, 15.

16 Al-Sader, B. H.; Al-Fekri, D. M. J. Org. Chem. 1978, 43, 3627. 

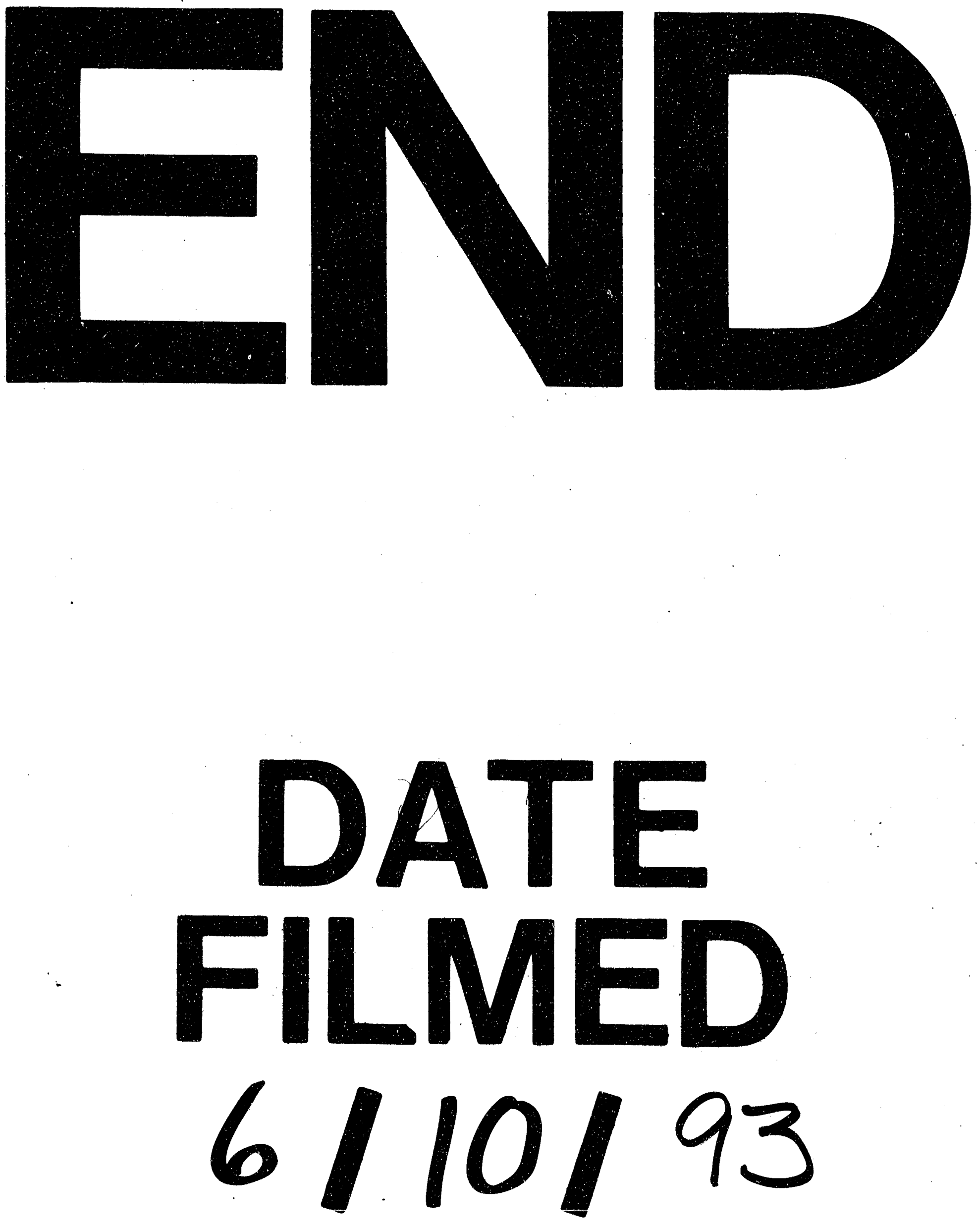
